\title{
Bestimmung von Fehlverklebungen mittels Schallaufzeitmessung
}

\section{P. Niemz}

Universidad Astral de Chile Valdivia, Chile

Subject Determination of glue joint defects in laminated materials using sound velocity measurements

Material and Methode Als Versuchsmaterial dienten gehobelte Bretter $(1000 \mathrm{~mm} \times 200 \mathrm{~mm} \times 20 \mathrm{~mm}$ ) der Holzart Roble (Nothofagus obliqua (Mirbel) Oerst).

Jeweils 10 Bretter wurden mit PVAc-Kaltleim gemäß Bild 1 so zu einem Block verklebt, daß gezielt Fehlverklebungen entstanden und daß sich der Anteil der Fehlverklebungen von Schicht zu Schicht um je $10 \mathrm{~cm}$ erhöhte.

Senkrecht zur Faserrichtung wurde die Schallgeschwindigkeit mittels Silvatest (Frequenz $16 \mathrm{kHz}$ ) bestimmt. Die Messungen erfolgten unmittelbar nach dem Aushärten des Klebstoffes (nach 12 Stunden) und nach mehrtägiger Konditionierung.

Ergebnisse Bild 1 zeigt die Versuchsergebnisse. Mit zunehmendem Anteil an nicht verleimten Lagen, d.h. Zunahme der Übergänge

Sender

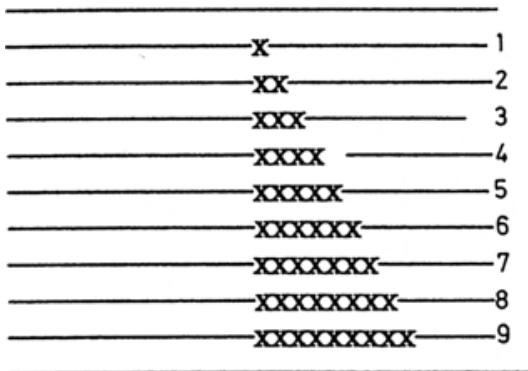

Empfänger

Bild 1. Versuchsaufbau mit 9 Leimfugen $x$ - unbeleimte Fläche

Fig. 1. Measuring sound velocity between 9 glue joints $x-$ not glued area
(Holz/Luft) sinkt die Schallgeschwindigkeit deutlich ab. Durch die Konditionierung der Proben kommt es offensichtlich zu einer Verringerung des Luftspaltes zwischen den fehlerhaft verleimten Lameilen (z.B. durch Quellungs- und/oder Relaxationserscheinungen) und damit zu einem Anstieg der Schallgeschwindigkeit. Mehrere Wiederholungsmessungen an solcherart verleimten Elementen zeigten stets die gleiche Tendenz, aber graduelle Unterschiede, die wesentlich durch die verwendeten Brettlamellen (elastomechanische Eigenschaften, Anfangskrümmung etc.) beeinflußt wurden. Das Meßprinzip eignet sich für die Bestimmung der Verklebungsgüte. Weitere Arbeiten zur Optimierung des verwendeten Versuchsaufbaus (z.B. Meßfrequenz) sind erforderlich.

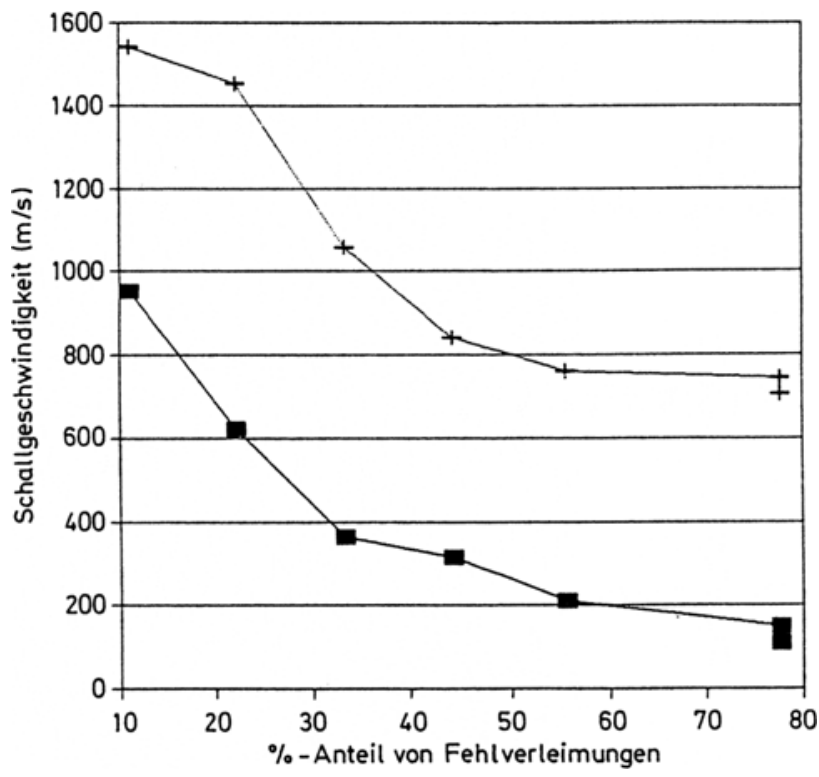

Bild 2. Einfluß des Anteils unbeleimter Fugen auf die Schallgeschwindigkeit bei Durchschallung senkrecht zur Faserrichtung

- Messung 1 nach $16 \mathrm{~h} ;+$ Messung 2 nach $96 \mathrm{~h}$

Fig. 2. Influence of the amount of glue joint defects (\%) on sound velocity $(16 \mathrm{kHz})$ perpendicular to grain

Measurement after $16 \mathrm{~h} \mathrm{(})$ and $96 \mathrm{~h}(+)$ 